\title{
Sequential Metal-free Thermal 1,3-Dipolar Cycloaddition of Unactivated Azomethine Ylides
}

\author{
Verónica Selva, ${ }^{\mathrm{a}, \mathrm{b}, \mathrm{c}}$ Elisabet Selva, ${ }^{\mathrm{a}, \mathrm{b}, \mathrm{c}, \mathrm{d}}$ Pedro Merino, ${ }^{\mathrm{e}}$ Carmen Nájera, ${ }^{* a, b}$ and José M. Sansano, ${ }^{\text {a,b,c }}$ \\ a Departamento de Química Orgánica. Facultad de Ciencias, Universidad de Alicante, 03080-Alicante, Spain. \\ ${ }^{\mathrm{b}}$ Centro de Innovación en Química Avanzada (ORFEO-CINQA). \\ ${ }^{\mathrm{c}}$ Instituto de Síntesis Orgánica (ISO). \\ ${ }^{\mathrm{d}}$ Medalchemy, S. L. Avenida Ancha de Castelar, 46 - EA, San Vicente del Raspeig, 03690, Alicante. \\ e Instituto de Biocomputación y Física de Sistemas Complejos (BIFI). Universidad de Zaragoza, 50009 Zaragoza, Spain
}
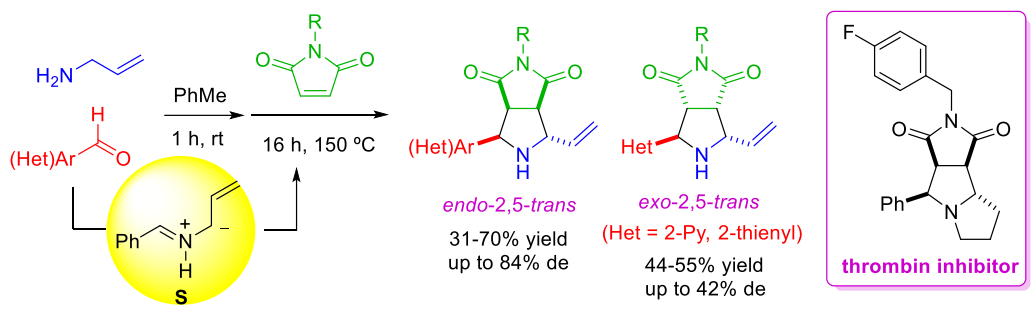

\begin{abstract}
The thermal 1,3-dipolar cycloaddition of unactivated azomethine ylides derived from allylamine and aromatic or heteroaromatic aldehydes with maleimides and 1,1- and 1,2-bis(phenylsulfonyl)ethylene affords endo-2,5-trans cycloadducts in moderate to good yield. DFT calculations provide evidences that the reaction is under thermodynamic control; thus, the final diastereomeric ratio observed depends on the stability of the final adducts rather than the corresponding transition structures (kinetic control). This methodology is applied to the diastereoselective synthesis of a tricyclic thrombin inhibitor.
\end{abstract}

Classical thermal 1,3-dipolar cycloadditions (1,3-DCs) are performed with activated dipolarophiles and stabilized or non stabilized dipoles. ${ }^{1,2}$ The generation of non-stabilized azomethine ylides by condensation of amino acids and aldehydes requires the use of $\mathrm{N}$-alkyl amino acids and aldehydes, to generate the corresponding non-stabilized iminium-type dipole I after decarboxylation (Scheme 1, eq. a). However, 1,2-prototropy shift processes allow the thermal generation of the stabilized dipoles II directly from the preformed imino esters derived from primary $\alpha$-amino acids (Scheme 1, eq. b). In both cases, an electrophilic alkene is ready to capture the fleeting dipole. ${ }^{1 \mathrm{~b}}$

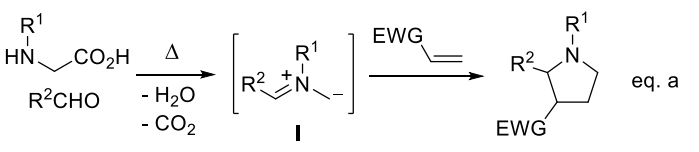

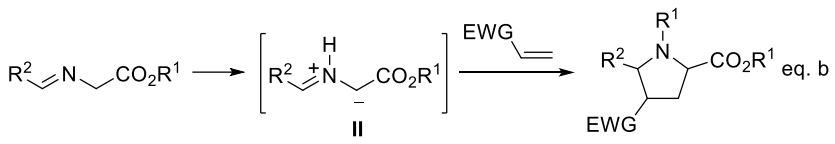

Scheme 1. 1,3-DC by Thermal Generation of Stabilized Azomethine Ylides

These traditional features have been disassembled by the publication of relevant contributions regarding non-classical components. For instance, a 2-pyridyl group was strategically placed instead of the ester group of the imino ester moiety $\mathbf{1}^{3}$ performing the cycloaddition in the presence of a chiral copper(I) complex. Lithium azaallyl anions III, ${ }^{4-10}$ introduced by Kauffmann, ${ }^{4}$ generated from imines $\mathbf{2 - 4}$ and strong bases as LDA and BuLi at very low temperature forced the HOMOLUMO approach to promote 1,3-DC even with non-activated dipolarophiles (Scheme 2). ${ }^{6}$ Thus, reactions between 2 and alkenyl arenes ${ }^{5,7}$ or dienes ${ }^{8}$ or hetero-substituted olefins, ${ }^{9}$ starting compounds 3 with alkenyl arenes, ${ }^{10} \mathbf{4}$ and conjugated polyenes, ${ }^{8}$ and the highly chelated lithium 2 -aza-allyl anions III with styrenes and other aliphatic olefins in the presence of $\mathrm{Me}_{2} \mathrm{AlCl} .{ }^{11}$

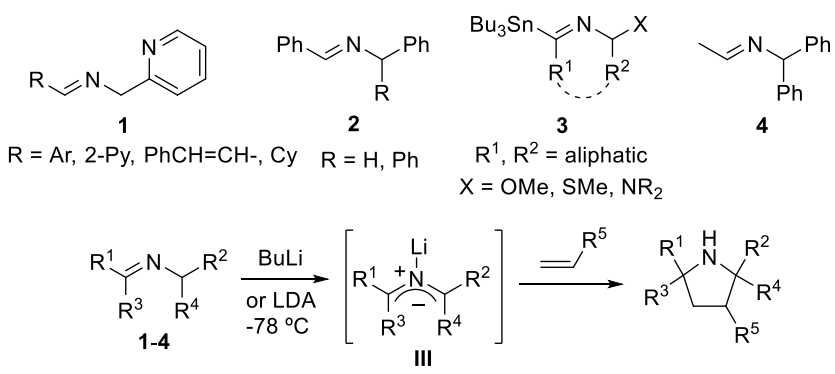

Scheme 2. 1,3-DC Involving Non-activated Azomethine Ylides

We envisaged the possibility of generate non-stabilized azomethine ylides by promotion of a thermal 1,2-prototropy shift on imines derived from allylamine and aromatic and heteroaromatic aldehydes for the diastereoselective synthesis of 2-vinyl5 -arylpyrrolidines, precursors of thrombin inhibitors (Scheme 3). ${ }^{12}$

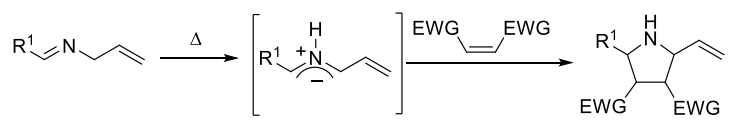

Scheme 3. Proposed 1,3-DC Involving Non-activated Azomethine Ylides Derived from Allylamine

Imine 5a was initially tested in the presence of $N$-methylmaleimide (NMM) using different conditions described in Table 1. 
Following previous thermal cycloadditions reported by our group,$^{13}$ toluene was selected as solvent. As it is depicted in Table 1 , imine 5a in the presence of $5 \mathrm{~mol} \%$ of trimethylamine and silver benzoate at $90^{\circ} \mathrm{C}$ gave a ca. $1: 1$ mixture of endo-2,5trans and endo-2,5-cis diastereomers 6aa in low conversion (Table 1, entry 1). However, when $30 \mathrm{~mol} \%$ of benzoic acid was added to catalyze the process, rather than trifluoroacetic acid and $p$-toluenesulfonic acid high conversion was observed giving 6aa in $95 \%$ (Table 1, entries 2-4). In the absence of acid the reaction failed (Table 1, entry 5). When the amount of benzoic acid was increased to $1 \mathrm{eq}$, the conversion was $90 \%$ (Table 1 , entry 6). On the other hand, an increment of the temperature decreased the reaction time rising full conversions in the presence or absence of $30 \mathrm{~mol} \%$ of benzoic acid at $150{ }^{\circ} \mathrm{C}$ in $16 \mathrm{~h}$ (Table 1, entries 7 and 8). Using a lower temperature $130{ }^{\circ} \mathrm{C}$ (Table 1, entry 9) and lower reaction time $(7 \mathrm{~h})$ at $150^{\circ} \mathrm{C}$ (Table 1 , entry 10) did not improve the previous result. The thermal process without additives afforded cleaner crude reaction products. With respect to the observed diasteroselectivity similar results were observed in most of the cases.

Table 1. Optimization of reaction conditions of 1,3-DC of 5 with NMM
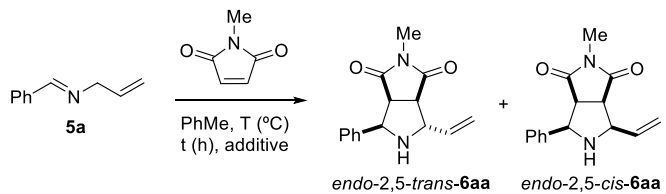

$\begin{array}{lllllll}\begin{array}{l}\text { en- } \\ \text { try }\end{array} & \text { imine } & \begin{array}{r}\text { additive } \\ (\mathrm{mol} \%)\end{array} & \begin{array}{c}\mathrm{T} \\ \left({ }^{\circ} \mathrm{C}\right)\end{array} & \begin{array}{c}\text { time } \\ (\mathrm{h})\end{array} & \begin{array}{c}\text { Conv. } \\ (\%)^{\mathrm{a}}\end{array} & \mathrm{dr} \\ 1 & \mathbf{5 a} & \begin{array}{l}\text { Et }{ }_{3} \mathrm{~N}(5), \\ \text { AgOBz }(5)\end{array} & 90 & 48 & 15 & 45: 55 \\ 2 & \mathbf{5 a} & \text { BzOH (30) } & 90 & 48 & 95 & 68: 32 \\ 3 & \mathbf{5 a} & \text { TFAA (30) } & 90 & 72 & 11 & 53: 47 \\ 4 & \mathbf{5 a} & p \text {-TsOH (30) } & 90 & 72 & 39 & \mathrm{~b} \\ 5 & \mathbf{5 a} & - & 90 & 48 & - & - \\ 6 & \mathbf{5 a} & \text { BzOH (100) } & 110 & 16 & 90 & 65: 35 \\ 7 & \mathbf{5 a} & \text { BzOH (30) } & 150 & 16 & 100 & 67: 37 \\ 8 & \mathbf{5 a} & - & 150 & 16 & 100 & 69: 31 \\ 9 & \mathbf{5 a} & - & 130 & 16 & - & - \\ 10 & \mathbf{5 a} & - & 150 & 7 & 58 & 64: 36 \\ 11 & -\mathrm{c} & - & 150 & 17 & 100 & 71: 29\end{array}$

${ }^{a}$ Determined by ${ }^{1} \mathrm{H}$ NMR of the crude reaction mixture. ${ }^{b}$ Mixture of 4 diastereomers. ${ }^{c}$ Sequential reaction: allylamine and benzaldehyde reacted during $1 \mathrm{~h}$ at $\mathrm{rt}$ and then NMM was added and stirring continued $16 \mathrm{~h}$ at $150{ }^{\circ} \mathrm{C}$.

When the reaction was carried out using a sequential process generating in situ the imine 5a, cleaner crude product 6aa in 71:29 dr was obtained (Table 1, entry 11). So, the thermal conditions in a two-step in situ process was employed to study the scope of the 1,3-DC to access molecules 6. However, when the reaction was performed in a three-component process a complex mixture of products was obtained.

The scope of the reaction was studied by the in situ prepared imine 5a by stirring a solution of allylamine and benzaldehyde in toluene for $1 \mathrm{~h}$ at rt. Next, the mixture was allowed to react with maleimide, $\mathrm{N}$-alkyl and $\mathrm{N}$-arylmaleimides affording the corresponding compounds 6aa-6ah as mixture of endo-2,5trans and endo-2,5-cis diastereoisomers with good conversions and moderate to good dr (Table 2, entries 1-8), which can be easily separated after flash chromatography affording the pure endo-2,5-trans 6 diasteromers. The chemical yield of the isolated major endo-2,5-trans diastereomer was good (41-70\%) and despite of the temperature reaction the best crude $\mathrm{dr}$ achieved corresponded to the process involving $N$-(o-methoxyphenyl)maleimide (Table 2, entry 5).

Table 2. Scope of the Thermal in situ Two-step 1,3-DC with maleimides

\begin{tabular}{|c|c|c|c|c|c|}
\hline Het)Ar & 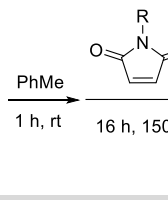 & endo-2,5-trans-6 & & $c i s-6$ & \\
\hline entry & $\mathrm{Ar}$ & $\mathrm{R}$ & 6 & $\mathrm{dr}$ & $\begin{array}{l}\text { yield } \\
(\%)^{\mathrm{b}, \mathrm{c}}\end{array}$ \\
\hline 1 & $\mathrm{Ph}$ & $\mathrm{Me}$ & 6aa & $71: 29$ & 67 \\
\hline 2 & $\mathrm{Ph}$ & $\mathrm{H}$ & 6ab & $69: 31$ & 62 \\
\hline 3 & $\mathrm{Ph}$ & $\mathrm{Bn}$ & $6 a c$ & $65: 35$ & 64 \\
\hline 4 & $\mathrm{Ph}$ & $\mathrm{Ph}$ & 6ad & $72: 28$ & 69 \\
\hline 5 & $\mathrm{Ph}$ & $2-\mathrm{MeOC}_{6} \mathrm{H}_{4}$ & 6ae & $92: 8$ & 70 \\
\hline 6 & $\mathrm{Ph}$ & $3-\mathrm{ClC}_{6} \mathrm{H}_{4}$ & 6af & $83: 17$ & 41 \\
\hline 7 & $\mathrm{Ph}$ & 4- $\mathrm{ClC}_{6} \mathrm{H}_{4}$ & 6ag & $76: 24$ & 68 \\
\hline 8 & $\mathrm{Ph}$ & 4- $\mathrm{BrC}_{6} \mathrm{H}_{4}$ & 6ah & $74: 26$ & 55 \\
\hline 9 & 2-Naphthyl & $\mathrm{Me}$ & $6 \mathbf{b a}$ & $58: 42$ & 60 \\
\hline 10 & $2-\mathrm{MeC}_{6} \mathrm{H}_{4}$ & $\mathrm{Me}$ & 6ca & $73: 27$ & 38 \\
\hline 11 & $3-\mathrm{MeC}_{6} \mathrm{H}_{4}$ & $\mathrm{Me}$ & 6da & $80: 20$ & 31 \\
\hline 12 & $4-\mathrm{MeC}_{6} \mathrm{H}_{4}$ & $\mathrm{Me}$ & 6ea & $77: 23$ & 40 \\
\hline 13 & $2-\left(\mathrm{NO}_{2}\right) \mathrm{C}_{6} \mathrm{H}_{4}$ & $\mathrm{Me}$ & $6 \mathbf{f a}$ & $76: 24$ & 41 \\
\hline 14 & $3-\left(\mathrm{NO}_{2}\right) \mathrm{C}_{6} \mathrm{H}_{4}$ & $\mathrm{Me}$ & 6ga & $66: 34$ & 62 \\
\hline 15 & 4- $\left(\mathrm{NO}_{2}\right) \mathrm{C}_{6} \mathrm{H}_{4}$ & $\mathrm{Me}$ & 6ha & $59: 41$ & 56 \\
\hline 16 & $4-\mathrm{BrC}_{6} \mathrm{H}_{4}$ & $\mathrm{Me}$ & 6ia & $69: 31$ & 62 \\
\hline 17 & 3-Pyridyl & $\mathrm{Me}$ & 6ja & $62: 38$ & 53 \\
\hline 18 & $\mathrm{Ph}$ & $\left(4-\mathrm{F}-\mathrm{C}_{6} \mathrm{H}_{4}\right) \mathrm{CH}_{2}$ & 6ai & $73: 26$ & 68 \\
\hline
\end{tabular}

${ }^{a}$ Determined by ${ }^{1} \mathrm{H}$ NMR of the crude reaction mixture. ${ }^{\mathrm{b}}$ Isolated yield after purification (flash silica gel) of the major endo2,5-trans-diastereoisomer. ${ }^{\mathrm{c}}$ The major diastereomer was obtained in $>99: 1 \mathrm{dr}$.

The series of $\mathrm{N}$-arylidene allylimines depicted in entries 916 of the Table 2 were also appropriate to run this 1,3-DC with NMM. Mixtures of endo-2,5-trans:endo-2,5-cis diastereomers were achieved using independently $o-, m$ - or $p$-substituted azomethine ylide precursors $\mathbf{6 b}-\mathbf{i}$ affording high combined chemical yields except for the family of tolyl moieties where yields remained lower. The 3-pyridyl derivative also afforded a high overall chemical yield of the 69:31 endo-2,5-trans-6ja: endo2,5-cis-6ja mixture (Table 2, entry 17). At this point, product endo-2,5-trans-6ja could be separated and recrystallized obtaining an X-ray diffraction pattern. ${ }^{14}$ nOe experiments and ${ }^{1} \mathrm{H}$ NMR coupling constants confirm this structural analysis. In addition, the relative configurations of all-cis-endo-6 products were analogously determined (see supporting information). Finally, $N$-(4-fluorobenzyl)maleimide ${ }^{15,16}$ was tested in this reaction affording a 69:31 mixture of endo-2,5-trans-6ai : endo-2,5cis-6ai (Table 2, entry 18) and good yield and higher diastereoselectivity of the major isomer after purification by column chromatography (88:12 dr). Cycloadduct endo-2,5-trans-6ai was furtherly used for the synthesis of a thrombin inhibitor (see below).

A different diasteroselective facial outcome was observed in the case of the cycloadditions with 2-pyridine and 2-thienylcarbaldehyde. In these cases, exo- and endo-2,5-trans 6ka and 6la cycloadducts were obtained, respectively (Scheme 4). Compound 6ka was obtained in a 67:33 dr affording after purification the exo-2,5-trans-6ka isomer in $44 \%$ yield. Whereas, in the case of the thiophene derivative a mixture 71:29 of exo:endo6la was obtained, which after chromatographic purification afforded exo-2,5-trans-6la in 55\% yield. 


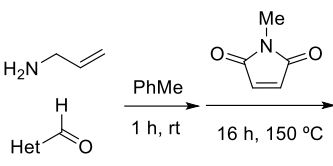
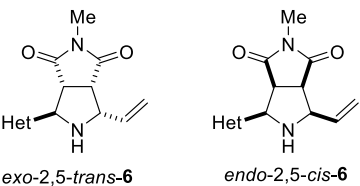

exo-2,5-trans-6

6ka: Het $=2$-Pyridyl: $44: 23 \mathrm{dr}, 44 \%$ yield

Scheme 4. 1,3-DC of Imines 5k and 5l with NMM

Despite attempting a large number of dipolarophiles using this methodology only bis(phenylsulfonyl)ethylene (BPSE) family gave a notable conversion. Surprisingly, 1,1- and 1,2(BPSE) afforded the same cycloadducts endo-2,5-trans 7a and endo-2,5-cis-7a in different proportion in the crude mixture (56:44 and 70:30 endo-2,5-trans 7a and endo-2,5-cis-7a, respectively, Scheme 5). After purification product endo-2,5trans-7a was exclusively obtained with this relative configuration, which was determined by comparison of its coupling constants a nOe with the analogous results obtained for other endo2,5-trans-isomers (see above). The formation of isomer 7a during the transformation with 1,1-BPSE could be due to a cycloaddition-elimination-Michael type addition of benzenesulfinate anion sequence. ${ }^{17}$

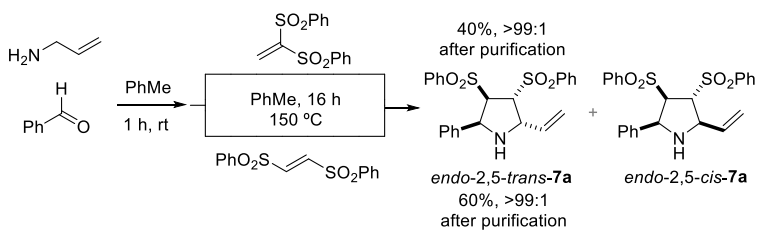

Scheme 5. 1,3-DC of Imine 5a with 1,1- and 1,2-BPSE

The key reaction between the in situ formed non-stabilized azomethine ylide and NMM was studied in detail by DFT methods to provide a rationale of the observed diastereoselectivity. The four possible conformations of the ylide (S, W, S' and U), which can stabilize the negative charge at either the allylic or the benzylic position, as well as endo and exo approaches were evaluated. A total of eight transition structures leading to the four possible adducts were located for the reaction of the azomethine ylide derived from benzaldehyde (Scheme 6).

The relative energies of reactants, transition structures and products are collected in Table 3 (for detailed data and geometries, see SI). According to the values showed in Table 3 the preferred transition structure corresponds to TS3-endo, leading to endo-2,5-cis adduct, the expected product provided the reaction is under kinetic control. However, this result is not in agreement with the experimental observations. On the other hand, taken into consideration the stability of the final adducts, the most stable structure corresponds to the endo-2,5-trans adduct, which is the major product observed experimentally. Moreover, the inverse barriers are in the order of ca. $30 \mathrm{kcal} / \mathrm{mol}$, a value that can be reachable at the temperature $\left(150{ }^{\circ} \mathrm{C}\right)$ to which the reaction is carried out. These results suggest that the reaction is under thermodynamic control. Consequently, the preferred transition structure corresponding to the most reactive ylide conformation is irrelevant, the only factor governing the diastereomeric ratio of the reaction being the stability of the final products.

The study was extended to the azomethine ylides derived from 2-pyridyl- and 2-thienylcarboxaldehyde. Again, the experimental results are more in agreement with a thermodynamic control, although the low differences between the relative energies of the products $(c a .1-2 \mathrm{kcal} / \mathrm{mol}$, which are within the DFT error) do not allow a quantitative analysis of the diastereomeric ratio. Admittedly, the observed differences in diastereoselectivity cannot be assessed by DFT calculations which only predict that mixtures of adducts will be obtained. On the other hand, the presence of (un)favorable interactions evidenced by NCI topological calculations can justify the observed trends towards the exo adduct in the case of 2-pyridyl and 2-thienyl derivatives (see SI).
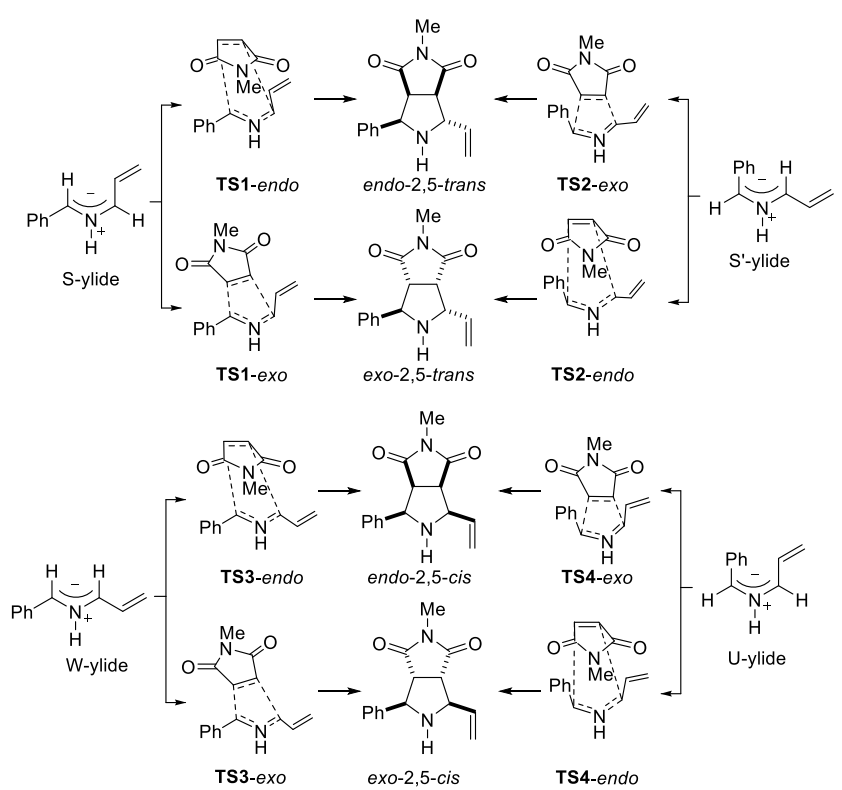

Scheme 6. Reaction pathways for the cycloaddition of non-stabilized Azomethine Ylides

Table 3. Absolute (hartree) and relative ( $\mathrm{kcal} / \mathrm{mol}$ ) free energies $^{\text {a }}$ for the reaction of ylide derived from benzaldehyde and NMM

\begin{tabular}{lccc}
\hline & $\mathrm{G}$ & $\Delta \mathrm{G}^{\mathrm{b}}$ & Imaginary frequency \\
\hline NMM & -398.866809 & & \\
S-ylide & -442.432902 & & \\
S'-ylide & -442.432884 & & \\
W-ylide & -442.436343 & & \\
U-ylide & -442.425451 & & \\
TS1-endo & -841.293053 & 6.3 & -260.4 \\
TS2-endo & -841.290929 & 7.7 & -254.7 \\
TS3-endo & -841.295888 & 4.6 & -208.5 \\
TS4-endo & -841.281165 & 13.8 & -274.8 \\
TS1-exo & -841.288470 & 9.2 & -259.7 \\
TS2-exo & -841.287269 & 10.0 & -276.1 \\
TS3-exo & -841.293894 & 5.8 & -217.4 \\
TS4-exo & -841.276113 & 17.0 & -269.0 \\
endo-2,5-cis & -841.347296 & -27.7 & \\
endo-2,5-trans & -841.348026 & -28.2 & \\
exo-2,5-cis & -841.345979 & -26.9 & \\
exo-2,5-trans & -841.346432 & -27.2 & \\
\hline
\end{tabular}

${ }^{a}$ Calculated at b3lyp-gd3bj/def2tzvp/pcm =toluene/temp $=448$ $\mathrm{K} / / \mathrm{b} 31 \mathrm{yp}-\mathrm{gd} 3 \mathrm{bj} / / \mathrm{def} 2 \mathrm{svp} .{ }^{\mathrm{b}}$ Referred to NMM and the most stable conformation of the ylide (according to Curtin-Hammett principle).

A direct application of this methodology consisted in a short synthesis of a tricyclic thrombin inhibitors 9 (Scheme 7). ${ }^{12}$ In this case, the thermal 1,3-DC was run with $\mathrm{NMM}^{20}$ and $\mathrm{N}$-(4fluorobenzyl)maleimide (Table 2, entries 1 and 20). Compounds endo-2,5-trans-6aa and endo-2,5-trans-6ai, which possessed the right configuration to access the desired compound 9, were submitted to the allylation of the nitrogen atom followed 
by ring closing metathesis using the $2^{\text {nd }}$ generation HoveydaGrubbs' catalyst. ${ }^{21}$ Intermediate compounds 8aa and 8ai were isolated in 70 and $69 \%$ chemical yields, respectively. Final hydrogenation of the double bond only was carried out onto 8ai under mild conditions [rt, $\mathrm{H}_{2}$ (1 atm), $\mathrm{Pd} / \mathrm{C}(10 \% \mathrm{Pd}, 8$ $\mathrm{mg} / \mathrm{mmol}$ of substrate $]^{21}$ affording quantitatively compound 9ai (Scheme 7). The overall yield of 9ai, achieved from allylamine, was $47 \%$.

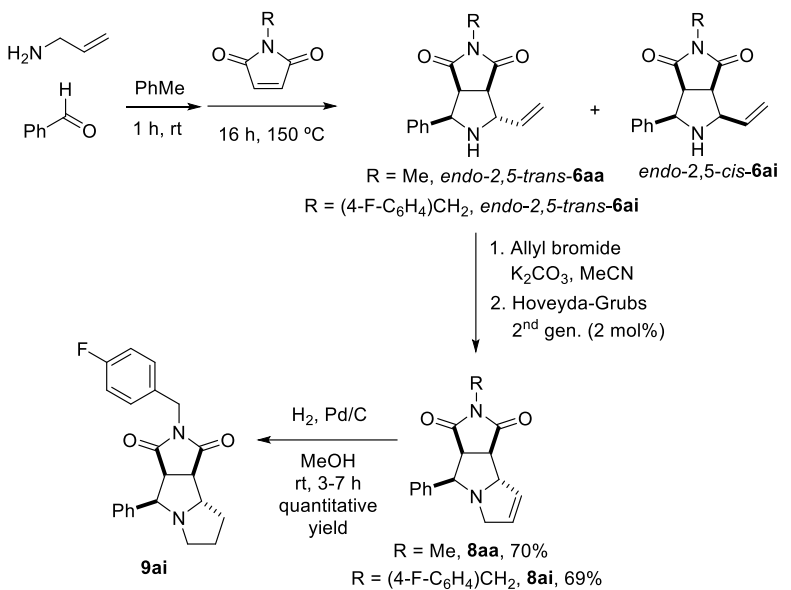

Scheme 7. Synthesis of the tricyclic thrombin inhibitor 9ai

In conclusion, a thermal allylic $\mathrm{C}-\mathrm{H}$ activation was successfully promoted in the in situ prepared $\mathrm{N}$-benzylideneallylamine. The driving force of this activation is the generation of an intermediate azomethine ylide that reacts with the dipolarophile under thermodynamic control. The conformation of the ylide and

\section{References}

For reviews dealing with general 1,3-DC, see: (a) Baunach, M.; Hertweck, C. Angew. Chem. Int. Ed. 2015, 54, 12550-12552; (b) Singh, M.S.; Chowdhury, S.; Koley, S. Tetrahedron 2016, 72, 1603-1716; (c) Pandey, G.; Dey, D.; Tiwari, S. K. Tetrahedron Lett. 2017, 58, 699705. For general reviews dealing with asymmetric 1,3-DC, see: (d) Li, J.; Zhao, H.; Zhang Y. Synlett 2015, 26, 2745-2750; (e) Yoo, E. J. Synlett 2015, 26, 2189-2193; (f) Ryan, J. H. Arkivoc 2015, (i), 160-183; (g) Hashimoto, T.; Maruoka, K. Chem. Rev. 2015, 115, 5366-5412; (h) Pavlovska, T. L.; Gr. Redkin, R.; Lipson, V. V.; Atamanuk, D. V. Synth. Biol. Activ. Mol. Divers 2016, 20, 299-344; (i) Meyer, A. G.; Ryan, J. H. Molecules 2016, 21, 935-989; (j) Nájera, C.; Sansano, J. M. Chem. Record 2016, 16, 2430-2448; (k) Dondas, H. A.; Retamosa, M. G.; Sansano, J. M. Synthesis 2017 49, 2819-2851; (1) Bdiri, B.; Zhao, B.-J.; Zhou, Z.-M. Tetrahedron: Asymmetry 2017, 28, 876-899.

2 For cycloadditions of 1,n-dipoles, see: De, N.; Yoo, E. J. ACS Catal. 2018, $8,48-58$.

Padilla, S.; Tejero, R.; Adrio, J.; Carretero, J. C. Org. Lett. 2010, 12, 5608-5611.

4 Kauffmann, T.; Berg, H.; Köppelmann, E. Angew. Chem., Int. Ed. Engl. 1970, 9, 380-393.

6 Otero-Fraga, J.; Montesinos-Magraner, M.; Mendoza, A. Synthesis 2017, 49, 802-809.

7 (a) Kauffmann, T. Angew. Chem., Int. Ed. Engl. 1974, 13, 627-639; (b) Kauffmann, T.; Habersaat, K.; Koeppelmann, E. Chem. Ber. 1977, 110, 638-644; (c) Pandiancherri, S.; Lupton, D. W. Tetrahedron Lett. 2011, 52, 671-674.

8 (a) Kauffmann, T.; Eidenschink, R. Angew. Chem., Int. Ed. Engl. 1971, 10, 739-740; (b) Kauffmann, T.; Eidenschink, R. Chem. Ber. 1977, 110, 645-650; (c) Pearson, W. H.; Mans, D. M.; Kampf, J. W. J. Org. Chem. 2004, 69, 1235-1247; (d) Bower, D. J.; Howden, M. E. H. J. Chem. Soc., Perkin Trans. 1 1980, 672-674; (e) Pearson, W. H.; Mans, D. M.; Kampf, J. W. Org. Lett. 2002, 4, 3099-3102.

(a) Popowski, E. Z. Chem. 1974, 14, 360-367; (b) Kauffmann, T.; Ahlers, H.; Hamsen, A.; Schulz, H.; Tilhard, H. J.; Vahrenhorst, A. Angew. Chem., Int. Ed. Engl. 1977, 16, 119-119; (b) Kauffmann, T.; the corresponding transition structures are irrelevant, the only factor governing the stereochemical outcome of the reaction being the stability of the final adducts. This methodology can be successfully applied to the synthesis of a tricyclic thrombin inhibitor 9ai in three steps with an overall yield of $47 \%$, which is higher than the reported ones.

\section{ASSOCIATED CONTENT}

The Supporting Information is available free of charge on the ACS Publications website at DOI: Computational methods, details on computational calculations including energies, optimized geometries, NCI topological calculations and cartesian coordinates. Experimental details, characterization data, and NMR spectra for new compounds (PDF), computational data and $\mathrm{X}-\mathrm{RD}$ analysis.

\section{AUTHOR INFORMATION}

*E mail: cnajera@ua.es; *E mail: jmsansano@ua.es The manuscript was written through contributions of all authors.

\section{ACKNOWLEDGMENTS}

Dedicated to Prof. Ernesto Carmona on the occasion of his $70^{\text {th }}$ birthday. We gratefully acknowledge financial support from the Spanish Ministerio de Economía y Competitividad (MINECO) Agencia Estatal de Investigación (AEI) and Fondo Europeo de Desarrollo Regional (FEDER, EU) (projects CTQ2013-43446-P, CTQ2014-51912-REDC, CTQ2016-76782P, CTQ2016-81797-REDC and CTQ2016-76155-R), the Generalitat Valenciana (PROMETEOII/2014/017), the University of Alicante and Medalchemy S. L. E. Selva thanks University of Alicante and Medalchemy S. L. for a predoctoral fellowship. We also thank Dr. T. Soler her help in the Xray diffraction analysis (SSTTI, University of Alicante). The authors thankfully acknowledge the resources from the supercomputers "Memento" and "Cierzo", technical expertise and assistance provided by BIFI-ZCAM (Universidad de Zaragoza, Spain).

Ahlers, H.; Echsler, K. J.; Schulz, H.; Tilhard, H. J. Chem. Ber. 1985 118, 4496-4506; (c) Pearson, W. H.; Mi, Y.; Lee, I. Y.; Stoy, P. J. Am. Chem. Soc. 2001, 123, 6724-6725.

10 (a) Pearson, W. H.; Stevens, E. P. J. Org. Chem. 1998, 63, 9812-9827; (b) Pearson, W. H.; Szura, D. P.; Postich, M. J. J. Am. Chem. Soc. 1992, 114, 1329-1345; (c) Pearson, W. H.; Lian, B. W. Angew. Chem. Int. Ed. 1998, 37, 1724-1726; (d) Pearson, W. H. Pure Appl. Chem. 2002, 74, 1339-1347; (e) Pearson, W. H.; Stoy, P. Synlett 2003, $903-$ 921; Pearson, W. H.; Stevens, E. P.; Aponick, A. Tetrahedron Lett. 2001, 42, 7361-7365.

11 Otero-Fraga, J.; Suárez-Pantiga, S.; Montesinos-Magraner, M.; Rhein, D.; Mendoza, A. Angew. Chem. Int. Ed. 2017, 12962-12966.

12 (a) Olsen, J.; Seiler, P.; Wagner, B.; Fischer, H.; Tschopp, T.; ObstSander, U.; Banner, D. W.; Kansy, M.; Müller, K.; Diederich, F. Org. Biomol. Chem. 2004, 2, 1339-1352; (b) Schweizer, E.; HoffmannRöder, A.; Schärer, K.; Olsen, J. A.; Fäh, C.; Seiler, P.; Obst-Sander, U.; Wagner, B.; Kansy, M.; Diederich, F. ChemMedChem 2006, 1 , 611-621.

13 Selva, V.; Larrañaga, O.; Castelló, L. M.; Nájera, C.; Sansano, J. M.; de Cózar, A. J. Org. Chem. 2017, 82, 6298-6312

14 The X-ray structures has been deposited in CCDC with reference 1820733

15 (a) Puerto Galvis, C. E.; Kouznetsov, V. V. Org. Biomol. Chem. 2013 , 11, 407-411; (b) Liu, G.-N.; Luo, R.-H.; Zhang, X.-J.; Zhou, Y.; Li, J.; Zheng, Y.-T.; Liu, H. Med. Chem. 2014, 4, 573-580.

16 Olsen, J. A.; Banner, D. W.; Seiler, P.; Wagner, B.; Tschopp, T.; ObstSander, U.; Kansy, M.; Müller, K.; Diederich, F. ChemBioChem 2004 5, 666-675.

17 1,1-BPSE was stable when maintained alone in toluene at $150{ }^{\circ} \mathrm{C} 24 \mathrm{~h}$. So, a transformation of 1,1-BPSE into 1,2-BPSE was discarded.

20 The reaction with NMM was done firstly in order to optimize the synthetic route for the preparation of the most interesting compound 10ai. In fact this $N$-methylated family stopped in compound $9 \mathbf{a a}$.

21 Iza, A.; Carrillo, L.; Vicario, J. L.; Badía, D.; Reyes, E.; Martínez, J. I. Org. Biomol. Chem. 2010, 8, 2238-2244. 